\title{
ARTIGOS
}

\section{VIABILIDADE DO TURISMO DE BASE COMUNITÁRIA NO PARQUE NACIONAL DA SERRA DO CIPÓ/MG. É POSSÍVEL?}

Euripedes Pontes Júnior ${ }^{1}$

Instituto Chico Mendes de Conservação da Biodiversidade

Geraldo Wilson Fernandes ${ }^{2}$

Universidade Federal de Minas Gerais

Resumo: O orçamento destinado pelo Governo Federal ao Instituto Chico Mendes de Conservação da Biodiversidade - ICMBio para que o mesmo faça a gestão das mais de 300 Unidades de Conservação (UC) Federais não é suficiente para uma excelência gerencial de tais áreas, o que tem imposto desafios crescentes para a sustentabilidade socio-econômico-ambiental das áreas protegidas. Uma das estratégias adotadas pelo ICMBio perante o desafio de gerir as UCs é a concessão de serviços turísticos em Unidades de Conservação para a iniciativa privada. Por outro lado, a atividade turística tem no espaço geográfico seu objeto de consumo, sendo que para que a mesma ocorra faz-se a apropriação dos territórios e redes, situação que, se não bem planejada, pode levar a uma ótica que privilegia classes mais abastadas em detrimento do local, que fica com o ônus social, ambiental e financeiro. Apesar dos estudos disponíveis na literatura demonstrarem a importância do Turismo de Base Comunitária - TBC enquanto justiça ambiental, percebe-se a escassez de dados sobre o viés da sustentabilidade econômica de tais iniciativas. O artigo buscou, através de um estudo de caso, apresentar dados que demonstram a viabilidade econômica do TBC, de forma a enriquecer o debate sobre esta possibilidade de arranjo gerencial.

Palavras-chave: Concessão de serviços ecoturísticos, Gestão de Unidades de Conservação, Turismo de Base Comunitária

\section{VIABILITY OF COMMUNITY BASED TOURISM IN THE SERRA DO CIPÓ NATIONAL PARK. IS IT POSSIBLE?}

Abstract: The budget allocated by the Brazilian Government to the Chico Mendes Institute for Biodiversity Conservation - ICMBio - to manage more than 300 Federal Conservation Units (UC) is not enough to achieve excellence in the management of such areas. This has posed increasing challenges for the socio-economic-environmental sustainability of protected areas. One of the strategies adopted by ICMBio in the face of the challenge of managing UCs is the concession of tourism services by the private sector. On the other hand, tourism activity has its object of consumption in the geographic space, and for it to take place, territories and networks are approp riated, a situation that, if not well planned, can lead to increased privileges to higher class levels in detriment of lower class levels of the local communities, which bears the social, environmental and financial burden. Although the studies available in the literature demonstrate the importance of Community Based Tourism - TBC as environmental justice, there is a lack of data on the economic sustainability bias of such initiatives. The article sought, through a case study, to present data that demonstrate the economic viability of the TBC to enrich the de bate on this possibility of managerial arrangement.

Keywords: Conservation Units management; Community-based tourism, Concession of ecotourism services.

\section{VIABILIDAD DEL TURISMO COMUNITARIO EN EL PARQUE NACIONAL SERRA DO CIPÓ: ¿ES POSIBLE?}

Resumen: El presupuesto assignado por el Gobierno brasileño al Instituto Chico Mendes para la Conservación de la Biodiversidad - ICMBio - para administrar más de 300 Unidades Federales de Conservación (UC) no es suficiente para lograr la excelencia em el manejo de dichas áreas. Esto há planteado desafios crecientes para la sostenibilidad socioeconómica y ambiental de las áreas protegidas. Uma de las estratégias adoptadas por el ICMBio ante el desafio de la gestión de las UC es la concesión de servicios turísticos por parte del sector privado. Por outro lado, la actividad turística tiene su objeto de consumo en el espacio geográfico, y para que se lleve a cabo se apropian territórios y redes, situación que, si no se planifica bien, puede llevar a um aumento de privilégios a niveles de clase superiores em detrimento de los niveles de clase más baja de las comunidades locales, que soporta la carga social, ambiental y financeira. Aunque los estudios disponibles en la literatura demuestran la importancia del Turismo Comunitario (TBC) como justicia ambiental, faltan datos sobre el sesgo de sostenibilidad económica de tales inciativas. El artículo buscó, a través de un estúdio de caso, presentar datos que demuestren la viabilidad económica de la TBC para enriquecer el debate sobre esta posibilidad de ordenamiento gerencial.

Palabras clave: Manejo de Unidades de Conservación; Turismo Comunitario; Concesión de servicios de ecoturismo.

1. Mestre em Ciências Biológicas. Analista Ambiental. E-mail: euripedes.pontes@icmbio.gov.br. ORCID: http://orcid.org/0000-0003-1057-7180.

2. Pós-Doutor em Ecologia e Pesquisador 1A do CNPQ. E-mail: gw.fernandes@gmail.com. ORCID: https://orcid.org/00000003-1559-6049. 


\section{Referencial teórico}

O Instituto Chico Mendes de Conservação da Biodiversidade - ICMBio é a autarquia federal vinculada ao Ministério do Meio Ambiente responsável pela gestão de 334 Unidades de Conservação (UC) Federais. Juntas, estas UC's somam 78,9 milhões de hectares, equivalente a 9,1 \% da área territorial do Brasil, estando presente em mais de mil municípios (ICMBio, 2020). Entretanto, para a gestão destas áreas, o Instituto tem à disposição um orçamento da ordem de R\$700 milhões, muito aquém de suas necessidades. Destaca-se ainda que nos últimos dez anos o orçamento da área ambiental tem sofrido cortes sucessivos, sendo o ICMBio uma das autarquias mais afetadas (WWF, 2018).

Uma das formas que o ICMBio tem adotado para melhorar a gestão das Unidades de Conservação Federais é através da concessão de serviços ecoturísticos para empresas do ramo, a exemplo do que já acontece nos Parques Nacionais da Tijuca, Foz do Iguaçú, Fernando de Noronha, dentre outros. No ano de 2019 a visitação em Unidades de Conservação gerou R\$79 milhões, cerca de $11 \%$ do orçamento do ICMBio. Deste recurso, 80\% adveio de apenas duas UCs: o Parque Nacional de Foz do Iguaçu e o Parque Nacional da Tijuca (ICMBio, 2020).

Apesar de poderem ser citados diversos aspectos positivos desta estratégia, a exemplo da maior estruturação das unidades, aumento da arrecadação gerando maior aporte de recursos por fontes próprias, maior visibilidade das Unidades de Conservação junto a sociedade e geração de empregos (RODRIGUES \& ABRUCIO, 2019), diversos outros pontos demonstram que tal sistema precisa evoluir e apresentar melhorias. Rodrigues \& Godoy (2013) trazem o entendimento de que a concessão de serviços turísticos em UCs deve ser enxergada como uma oportunidade pela qual o Estado tenha a possibilidade de colocar em prática Políticas Públicas baseadas em Valores Constitucionais. Sobre Valores Constitucionais, cabe trazer o entendimento de Pita (2013) que, de acordo com a Constituição Federal, a ordem econômica e financeira, deve considerar a valorização do trabalho humano, a defesa do meio ambiente, bem como assegurar a todos existência digna, conforme os ditames da justiça social e a redução das desigualdades sociais.

Neste sentido, é importante ter o entendimento de que o turismo é uma prática social que tem no espaço geográfico seu principal objeto de consumo. Em decorrência disto, o turismo requer a adaptação dos territórios a suas demandas materiais e imateriais, provocando alterações ambientais e sociais. Desta forma, a atividade turística enquanto atividade econômica precisa ser planejada de forma sustentável para se reproduzir principalmente nos locais receptores do turismo, onde as consequências do mesmo são mais facilmente percebidas (CRUZ, 2003). Deve-se, portanto, analisar o alinhamento das concessões de serviços turísticos em UCs com a Missão Institucional do ICMBio, definida como "proteger o patrimônio natural e promover o desenvolvimento socioambiental". Desta forma, é necessário buscar dados sobre as externalidades (impactos positivos e negativos) das concessões tanto no ecossistema da Unidade de Conservação quanto nas comunidades locais, bem como para o Sistema como um todo objetivando analisar a contribuição destas para o alcance (ou não) dos objetivos maiores da Instituição. Apenas assim, poderá ser construído um sistema sólido e duradouro, no qual os benefícios são divididos de forma justa e sustentável.

Rodrigues \& Godoy (2013) demonstram que apesar da geração de receitas com o uso público através dos valores pagos pela concessão, há de se considerar que também geram-se despesas consideráveis, a exemplo de manutenção de trilhas, serviços de vigilância e limpeza, o que pode encarecer os custos com a gestão da UC onde se pratica a concessão. Pontes Junior (2016, p. 90) ao comparar despesas administrativas (sem pessoal) de Parques Nacionais em diferentes níveis de desenvolvimento da atividade turística, demonstra que Parques que possuem concessões ativas (ex: 
Tijuca) possuem despesas administrativas anuais de ordem muito superior as demais UCs. Em uma análise dos dados apresentados, tem-se que o Parque Nacional da Tijuca possui média de despesas administrativas da ordem de R\$4,5 milhões anuais, ao passo que em UCs com visitação em estágio inicial e não ordenada (ex: Parque Nacional da Serra do Cipó) tais despesas anuais giram na faixa de R\$300 mil. Já o Parque Nacional do Descobrimento, que não está aberto à visitação, mantém suas despesas administrativas na faixa de R\$192 mil anuais. Observa-se com isto que as despesas administrativas do Parque Nacional da Tijuca equivalem a 15 UC similares ao Cipó ou a 23 equivalentes ao Descobrimento.

Sobre o monitoramento e avaliação dos contratos de concessão o relatório n 201601851 do Ministério da Transparência e Controladoria Geral da União demonstra haver certa fragilidade dos controles em relação ao faturamento das empresas concessionárias. Neste relatório é citado também que o recurso advindo das concessões é utilizado pelo ICMBio de forma geral, não apenas nas Unidades geradoras de tal recurso, sendo boa parte do mesmo aplicado em contratos administrativos diversos (MTCGU, 2016). Em relação a gestão dos contratos administrativos do ICMBio utilizados no apoio da gestão das unidades de conservação, do qual parte do recurso advém dos contratos de concessões turísticas, observa-se o fato de que auditorias da Controladoria Geral da União - CGU demonstram que muito ainda se pode avançar para um uso mais eficaz e eficiente desta verba. Tais relatórios inclusive recomendam ao Instituto o desenvolvimento de áreas específicas para tratar de temas como Governança, Auditoria, Compliance, Accountability e Gestão de Riscos de forma a primar pelo bom uso do recurso público (ICMBio, 2020). Tem-se com isto que o recurso advindo das concessões alimenta um sistema que muito tem a melhorar em eficácia e eficiência no uso da verba pública. Logo, apenas uma análise sistêmica poderá trazer elementos para um entendimento mais robusto sobre a contribuição dos recursos advindos das concessões para a Instituição.

Com relação a impactos ambientais do turismo no interior e entorno das UC e possível desalinhamento com a Missão Institucional, cita-se a sobre-exploração dos atrativos, alterações no comportamento da fauna devido a poluição sonora, luminosa e química, depósito irregular de resíduos sólidos e líquidos, compactação e erosão em trilhas com consequente assoreamento de corpos d'água, possibilidade de introdução de espécies exóticas, queimadas, dentre outros (SOARES, 2007). É comum no entorno dos Parques Nacionais onde se desenvolve o ecoturismo, um maior adensamento populacional, que por sua vez demanda mais recursos naturais para sua manutenção. Tais fatos representam um contrassenso, pois a UC que teve como um de seus objetivos frear a ocupação desordenada e uso não sustentável dos recursos ambientais acaba acelerando e ampliando tais impactos, a exemplo do que foi observado por Gontijo (2003) na região da Serra do Cipó/MG (veja também ALMADA et al, 2016).

Por outro lado, pelo viés social, há de se considerar que o modelo de contratação de pessoal para executar as tarefas ordinárias do contrato de concessão acaba repetindo padrões de achatamento de salários para os trabalhadores, que ficarão de certa forma presos a um cenário de estagnação econômica independente do crescimento da atividade (BOTELHO \& RODRIGUES, 2016).

Já com relação a impactos do turismo nas comunidades locais, a pesquisa de Amaral (2018) também na região da Serra do Cipó demonstrou que além da alteração de todo o espaço onde a mesma está inserida para permitir o turismo, incluindo a ressignificação de símbolos e lugares historicamente construídos, cita-se a especulação imobiliária que acaba expulsando os moradores tradicionais de suas propriedades e ainda direcionando-os para os trabalhos em pousadas e restaurantes, abandonando modos e tradições advindos de muitas gerações. Anaya \& Souza (2014) apresentam situações de conflitos ambientais territoriais no Parque Nacional da Serra do Cipó, 
demonstrando o impacto na criação da UC sobre comunidade local devido as diversas restrições do uso do solo e pressões para sua saída (primeiro ciclo de expropriação) bem como um segundo ciclo de expropriação relacionado a pressões para implantação de infraestruturas de turismo nas suas áreas.

A partir do quadro de impactos socio-econômico-ambientais da atividade turística concentrados na esfera local, que trazem desafios complexos para a gestão, e partindo do conceito de justiça ambiental para com as comunidades afetadas tanto pela criação da UC quanto pelo sistema hegemônico de concessão de serviços de turismo para grandes empresas do ramos, tem-se no Turismo de Base Comunitária (TBC) uma estratégia que pode contribuir sobremaneira tanto para uma melhoria das condições socioeconômicas da população local quanto para um melhor manejo ambiental da área, possibilitando maior equilíbrio na distribuição dos ônus e bônus da atividade junto as partes interessadas (BETTI \& DENARDN, 2013). Mielke \& Pegas (2013) citam exemplos de casos de sucesso de TBC não só em Unidades de Conservação, mas também nestas, a exemplo da Reserva de Desenvolvimento Sustentável Mamirauá, localizada na Amazônia, onde são percebidos benefícios econômicos, sociais e ambientais com o desenvolvimento da atividade. Por outro lado, os autores informam que mais de três quartos dos projetos de TBC são insustentáveis a longo prazo devido basicamente a três situações problema, sendo estas: acesso ao mercado, governança interna e gestão das parcerias estratégicas.

Sobre a questão da sustentabilidade dos TBC, há poucos estudos focados especificamente na demonstração da viabilidade financeira dos mesmos e, neste sentido, o presente estudo tem a intenção de contribuir com esta área ainda carente de dados, buscando analisar se um modelo hipotético de TBC em um Parque Nacional que possui o potencial de gerar renda para a comunidade local e com isto contribuir para o desenvolvimento social e o manejo ambiental adequado.

\section{Metodologia}

O estudo, uma primeira sistematização de dados, levou em conta a operacionalização dos serviços turísticos no Parque Nacional da Serra do Cipó por associação comunitária local, tendo por base os anos de 2018 e 2019, onde foram utilizados os dados da visitação obtidos no painel de informações do ICMBio (ICMBio, 2019). Para cada modalidade de serviço ecoturístico aferido, buscou-se parâmetros para balizar os valores de forma a condizer com a realidade.

Desta forma, para além do número de visitantes, utilizou-se um fator de correção para calibrar os dados de forma a corresponder a realidade da UC. A partir deste entendimento, foi realizado tanto o cálculo do potencial máximo do serviço (considerado aqui como a execução máxima diária da atividade por dia ao longo de todo o mês) bem como uma calibragem, esta calculada como 30\% do potencial máximo, que seria o equivalente a ocupação máxima do serviço nos finais de semana e feriados prolongados. Foram considerados como oportunidades de serviços o aluguel de bicicletas, charretes, cobrança de taxa de ingresso, taxa de travessia, receitas com lanchonete e restaurante.

O Parque Nacional da Serra do Cipó foi criado pelo Decreto 90.223/1984 e possui área de 33.800 ha, sendo circundado pela Área de Proteção Ambiental Morro da Pedreira, criada pelo Decreto 98.891/1990, possuindo 66.200 ha, sendo a área total das duas UCs de 100 mil hectares localizadas no Estado de Minas Gerais, Brasil (FIGURA 1). 
Figura 1 - Localização do Parque Nacional da Serra do Cipó

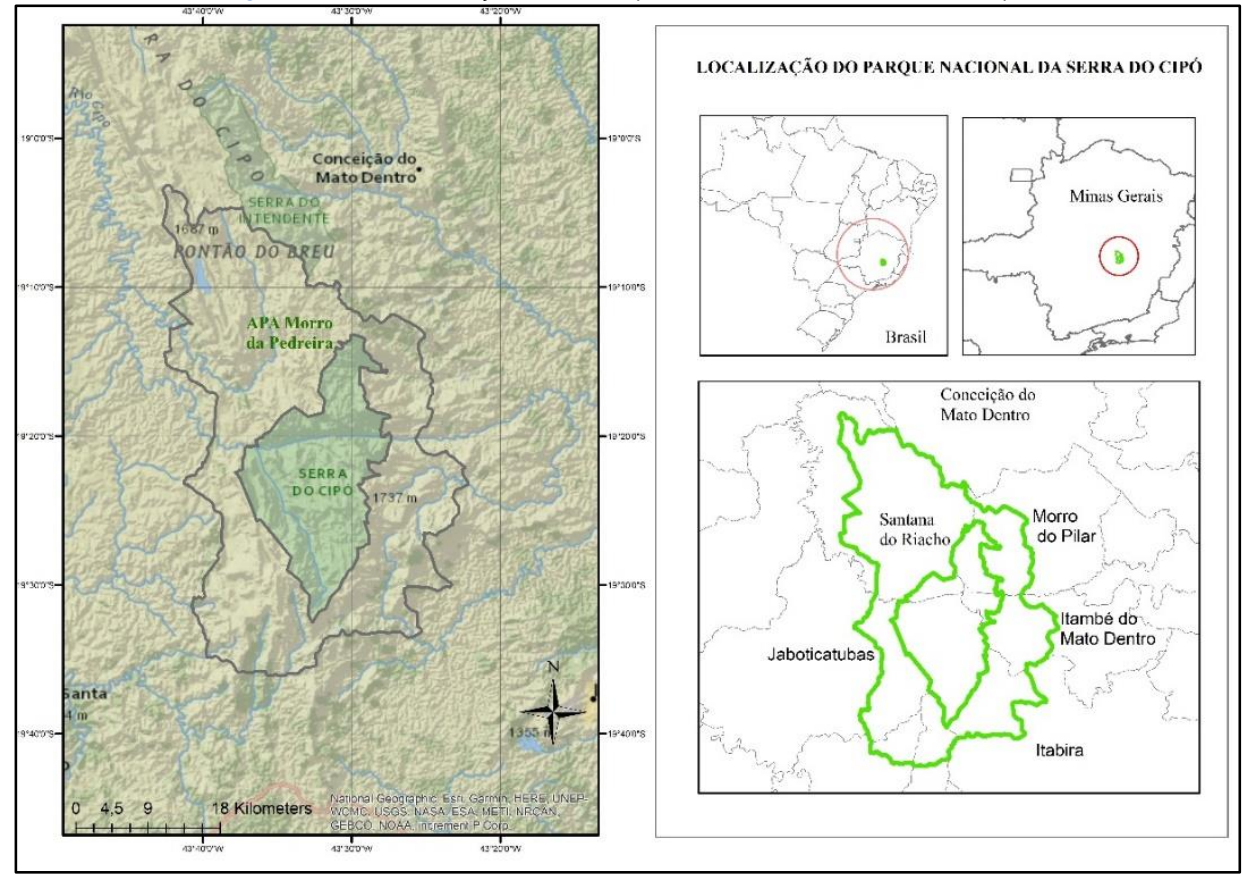

Fonte: elaborada pelos autores

\section{Resultados}

\section{Contexto local}

O objetivo de criação destas Unidades de Conservação está atrelado a grande biodiversidade presente na região, que é uma área de contato entre diferentes ecossistemas que possibilita a coexistência de espécies da Mata Atlântica e do Cerrado; notadamente da fauna e flora únicas do campo rupestre (ICMBio, 2009).

A Portaria ICMBio 848/2017 (ICMBio, 2017) criou o Núcleo de Gestão Integrada Cipó Pedreira, arranjo institucional que unificou a gestão do Parque Nacional da Serra do Cipó (PNSC) e da Área de Proteção Ambiental Morro da Pedreira (APAMP). Neste contexto, considerando o ano de 2019, em que a equipe das duas UCs (Cipó-Pedreira) totalizava 10 pessoas em efetivo exercício, tem-se que a média de hectares por servidor era de 10 mil hectares, comparável à mancha urbana de Criciúma/SC (IBGE, 2015).

Esta média relativamente alta tem reflexos negativos na gestão da área, dada a diminuição da capacidade operativa da gestão diante das inúmeras demandas a que as UCs estão sujeitas. Dentre reflexos negativos da diminuição da capacidade operacional das UCs podem ser citados a ocorrência de grandes incêndios florestais na UC, que em média atingem 6 mil hectares da UC (ou cerca de 1/5 da mesma) anualmente (ICMBio, 2019). Também a grande ocorrência de bovinos e muares pertencentes a terceiros pastando livremente no interior da UC e mesmo a lotação excessiva de atrativos naturais vêm denotar a baixa capacidade operacional da gestão em lidar com tais problemas (CARDOSO, 2008).

Com relação à estruturação de um serviço integrado de produtos e serviços turísticos, tem-se que tal serviço de concessão para uso público é inexistente. Até o ano de 2019 funcionava no Parque um sistema de autorização para aluguel de bicicletas e cavalos que por sua vez possui algumas anomalias no funcionamento. São exemplos de tais anomalias a utilização de cavalos no interior da UC contrariando o disposto no Plano de Manejo (ICMBio, 2009), a precariedade dos atos 
administrativos, que não passaram por ampla divulgação e concorrência, bem como aspectos falhos relacionados à gestão de uma Organização Social, a exemplo da ausência do registro de trabalhadores, pagamento de direitos trabalhistas, emissão de nota fiscal, dentre outros, como se depreende da leitura do processo administrativo específico da autorização (ICMBio, 2013). Também o monitoramento dos impactos da atividade não é sistematizado de forma procedimental com produção de relatórios situacionais.

Já com relação a infraestrutura, a UC dispõe apenas de uma sede administrativa construída em 1998 localizada no município de Jaboticatubas, onde foram feitas pequenas adaptações para recepção de turistas, a exemplo de guarita, um centro de visitantes, bebedouros, banheiros, porém não adequados ao volume crescente de turistas. A partir das portarias não há nenhuma estrutura de apoio (ICMBio, 2009).

O número de visitantes aumentou consideravelmente após a abertura da Portaria do Retiro, localizada no município de Santana do Riacho, em 2015, contendo uma precária estrutura para orientação ao turista. A média dos dois últimos anos foi de 80 mil visitantes registrados nestas duas portarias, tendo como média aproximada 6.500 visitantes por mês (FIGURA 2).

Figura 2 - Número de visitantes no Parque Nacional da Serra do Cipó entre 2014 e 2019

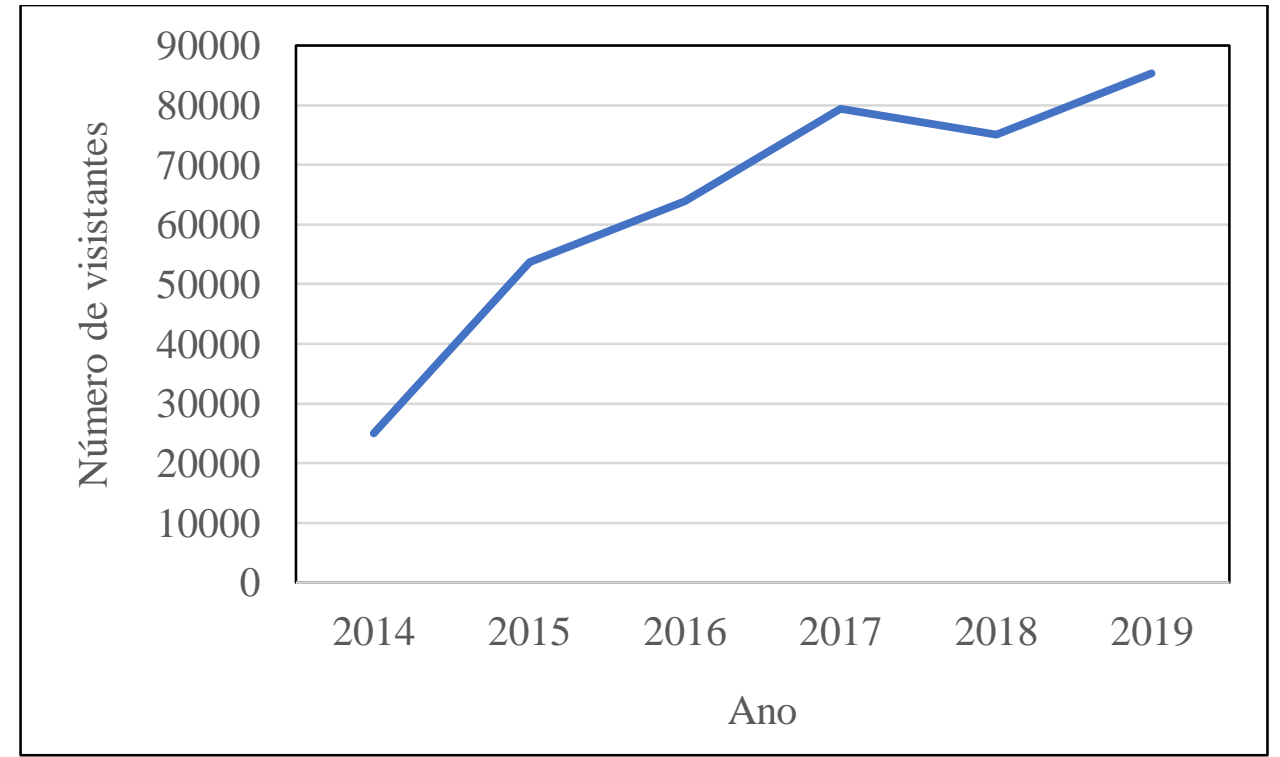

Como há alguns anos não se registra nenhum dado dos visitantes no Parque Nacional da Serra do Cipó, não há como contabilizar tais visitantes por categorias, como estrangeiros e brasileiros, crianças, adultos e idosos, fatores que normalmente são utilizados como parâmetros na cobrança de ingressos. Entretanto, por observação empírica, tem-se que aproximadamente $70 \%$ do público alvo se encaixa no perfil adulto, portanto apto a cobrança de ingresso. 


\section{Simulação da viabilidade do TBC no Parque Nacional da Serra do Cipó}

\section{Receitas}

Ingresso:

O Parque Nacional da Serra do Cipó atualmente não cobra ingresso para visitação, serviço que foi abolido no ano de 2011 pela gestão da época, apesar de tal serviço estar previsto no Plano de Manejo. Atualmente, segundo Portaria 831/2018 do Ministério do Meio Ambiente, o ingresso mais barato atualmente em vigor é aquele do Grupo 6, onde figura o Parque Nacional da Serra da Canastra, que possui cenário de área protegida semelhante ao Parque Nacional da Serra do Cipó. O ingresso neste grupo custa $\mathrm{R} \$ 10,00$, sendo este o valor do Desconto Brasil, que é o preço pago por brasileiros, que pagam metade do valor cobrado de estrangeiros. Tendo como base a estimativa de 6.500 visitantes/mês (216/dia), ao custo de R\$10,00/pessoa, tem-se o potencial de gerar até R\$65.000,00 mensais. Deste total mensal possível, decidiu-se por base empírica considerar viável que $70 \%$ do visitante do PNSC seja tido como público pagante ao preço do Desconto Brasil, ou seja, um total de 4.550 pessoas. Por outro lado, levou-se também em consideração que a cobrança de ingresso poderá vir a trazer uma redução inicial do número de visitantes dispostos a pagar tal taxa, tendo sido estimado, portanto uma redução de $50 \%$ do público pagante, o que reduziria então tal população de visitantes aptos a pagarem ingresso para 2.275 pessoas por mês. Desta forma a cobrança de ingresso no PNSC tem o potencial de gerar receitas da ordem de $\mathrm{R} \$ 22.750,00$ mensais.

Utilização de charretes no uso público:

Foram adquiridas 5 charretes a $\mathrm{R} \$ 10.000,00$ cada pelo Parque Nacional da Serra do Cipó em 2013 com recursos do Global Environmental Fund - GEF Cerrado visando apoiar a atividade de turismo equestre na unidade. A utilização das charretes objetiva atender a um público distinto e crescente que não tem a possibilidade de acessar os atrativos mais visitados da UC por estarem localizados a grandes distâncias, fato que por si só inviabiliza o acesso de portadores de necessidades especiais, crianças e idosos. Conforme processo administrativo específico, a viabilização de tal produto turístico se deu através de parceria com associação local de moradores através da disponibilização por parte destes de seus animais de montaria e da própria participação direta dos mesmos enquanto condutores.

Tendo por base o custo de $\mathrm{R} \$ 30,00 /$ pessoa que é cobrado na cidade turística de Tiradentes/MG e que a charrete comporta até 5 passageiros, a estimativa de geração renda máxima com esta atividade é de $\mathrm{R} \$ 150,00 /$ charrete/hora. Seguindo este raciocínio, o potencial máximo de geração de renda com as cinco charretes operando durante oito horas no dia será de $\mathrm{R} \$ 180.000,00$ mensalmente. Calibrando o valor acima em apenas 30\% do potencial máximo de forma a corresponder com a realidade da UC, que corresponde a utilização plena apenas nos finais de semana e feriados prolongados, tem-se a estimativa de faturamento com esta atividade no valor de $\mathrm{R} \$ 54.000,00$ mensais.

Instalação de espaços de alimentação:

Como outro exemplo cita-se a oportunidade gerada por espaços ociosos na sede administrativa do Parque Nacional da Serra do Cipó, contendo ambiente com salas, cozinha e despensas (edificação 
onde ficava localizado o antigo laboratório) bem como espaço apropriado para instalação de lanchonetes, associado ao fato de no presente momento (segundo semestre de 2019) não ser ofertado nenhum serviço de alimentação e souvenir no interior/portaria do Parque aos turistas.

Estima-se que do público calculado como pagante para o início do procedimento (2.275 pessoas por mês), apenas 30\% (682 pessoas) consumam produtos no restaurante/lanchonete a um custo de $\mathrm{R} \$ 30,00$ diário, considerando almoço a $\mathrm{R} \$ 20,00$ e lanche a $\mathrm{R} \$ 10,00$, o que gera então receitas mensais no valor de $\mathrm{R} \$ 13.650,00$.

Aluguel de bicicletas:

A Associação dos Amigos do Turismo da Serra do Cipó foi criada em 2015 pela comunidade local com a finalidade de ofertar serviços de aluguel de bicicletas e cavalos para servirem de apoio ao turista no interior do Parque Nacional da Serra do Cipó. A atividade foi autorizada pela gestão da UC e tem seu funcionamento de forma contínua desde então. Atualmente cerca de 8 pessoas participam ativamente do processo, sendo colocadas à disposição para aluguel cerca de 100 bicicletas, cujo valor médio gira em torno de R\$50,00/unidade/dia.

Tendo por base os valores acima, tem-se o potencial máximo da geração de renda com esta atividade nas atuais condições de R\$150.000,00 mensais. Deste total, considerou-se que o serviço de aluguel de bicicletas no PNSC deva operar na realidade com apenas 30\% da capacidade, resultando em um potencial de faturamento em torno de $\mathrm{R} \$ 45.000,00$ mensais.

Oferta de serviços de ecoturismo na trilha da travessia:

O Parque Nacional da Serra do Cipó possui uma travessia oficialmente implantada desde 2015, envolvendo um percurso que vai da localidade Alto Palácio (parte N/NO da UC, município de Morro do Pilar) até a localidade Serra dos Alves (situada a SE da UC), no município de Itabira, perfazendo um percurso de $40 \mathrm{~km}$, vencidos em um prazo de 3 dias. 0 percurso é realizado com duas pernoites no alto da serra em abrigos (precários) de montanha (Casa de Tábuas e Casa dos Currais). O número de pessoas em cada travessia é bastante variável, sendo permitido no máximo 30 pessoas, não se exigindo a necessidade de contratação de guias.

Assim como outros serviços, a travessia também não é cobrada pela UC. Em 2017 cerca de 1.500 pessoas fizeram a travessia devidamente autorizados, o que dá uma média de cerca de 100 pessoas por mês. Considerando uma estimativa de 90 pessoas/mês sendo R\$100,00/dia/pessoa, tem-se o potencial das travessias gerarem recursos da ordem de $\mathrm{R} \$ 27.000,00 / \mathrm{mês}$.

Potencial estimado de geração de receitas:

De acordo com os dados apresentados, o potencial de geração de receitas acima descritos (ingresso - R\$22.750,00; charretes - R\$54.000,00; alimentação - R\$13.650,00; bicicletas $\mathrm{R} \$ 45.000,00$ e travessias - $\mathrm{R} \$ 27.000,00)$, é estimado em $\mathrm{R} \$ 162$ mil mensais. 


\section{Despesas}

Manutenção geral:

Considerou-se como despesa uma taxa de 30\% do total das receitas obtidas (R\$162 mil) como sendo voltados para manutenção geral, o que resulta em despesas da ordem de $\mathrm{R} \$ 48.600,00$ mensais. Estima-se que tal valor cobriria as despesas com a manutenção de todos serviços acima descritos, como reparos de bicicletas, tratos veterinários, aquisição de gêneros alimentícios e produtos de limpeza, aquisição de insumos diversos, reparos de estruturas, dentre outros.

Pagamento de pessoal:

Tendo em vista que mesmo sendo uma associação, a execução de serviços por pessoal deve seguir a legislação afim, de forma a não se constituir uma ilegalidade. Desta forma, considerou-se como despesa o pagamento de pessoal responsável por operar os diversos serviços propostos, onde estimou-se um quadro com 28 pessoas para operar todo o sistema, divididos de acordo com o que consta na TABELA 01.

Tabela 1 - distribuição de funcionários por serviço
\begin{tabular}{|c|c|}
\hline Serviço & $\begin{array}{c}\text { Número de } \\
\text { funcionários }\end{array}$ \\
\hline Aluguel de bicicletas & 5 \\
\hline Aluguel de charretes & 5 \\
\hline Lanchonete & 4 \\
\hline Travessia & 8 \\
\hline Estacionamento & 2 \\
\hline Recepção de turista & 4 \\
\hline Total & 28 \\
\hline
\end{tabular}

Fonte: elaborada pelos autores

Tendo por base o valor da remuneração de um servente de limpeza nos contratos da Administração Pública Federal $(R \$ 1.124,50)$ e o custo de um posto de limpeza onde se considera para além do salário os benefícios ( $13^{\circ}$, férias, adicional de férias, vale transporte, auxílio alimentação, assistência familiar), encargos (previdenciários e FGTS), provisões para demissão e custos do profissional ausente, bem como insumos diversos (uniformes, materiais) e custos indiretos, tributos e lucro, tem-se o valor estimado de R\$4.056,73 (MINISTÉRIO DA ECONOMIA, 2019).

Considerando que no valor acima incluem-se impostos dos quais uma associação está isenta, a exemplo de Contribuição sobre Lucro Líquido - CSLL e Imposto de Renda Pessoa Jurídica - IRPJ bem como lucro, que juntos perfazem cerca de $20 \%$ do valor total, ou seja, cerca de $\mathrm{R} \$ 800,00$, é plausível aceitar uma despesa por trabalhador na faixa de R\$3.250,00. Neste contexto, as despesas com os 28 funcionários seriam da ordem de R\$91.000,00 mensais.

No valor acima está previsto as despesas com custos indiretos, como despesas administrativas, sendo consideradas na fórmula do custo de um posto de servente de limpeza como sendo cerca de $5 \%$ do valor total do posto conforme metodologia apresentada, que no caso então seria de $\mathrm{R} \$ 200,00$ por funcionário, num total de $\mathrm{R} \$ 5.600,00$ para o conjunto de 28 funcionários, valor este condizente com as despesas mensais a serem assumidas pela associação para sua manutenção administrativa. 
De acordo com os dados apresentados acima, o cálculo estimado das despesas (pessoal $\mathrm{R} \$ 91$ mil; manutenção (R\$49 mil), é de aproximadamente $\mathrm{R} \$ 140$ mil.

Resultado geral:

Com a metodologia acima descrita acerca do potencial do Parque Nacional da Serra do Cipó em gerar renda a partir de serviços e estruturas ociosas, tem-se uma estimativa de geração de receitas no valor de $\mathrm{R} \$ 162$ mil e despesas da ordem de valor de R\$140 mil, resultando em um fluxo de caixa positivo com lucro da ordem de R\$23 mil mensais, conforme TABELA 02.

\section{Tabela 2 - Resultado global da simulação financeira proposta de Turismo de Base Comunitária para o Parque Nacional da Serra do Cipó}

\begin{tabular}{|c|c|}
\hline Serviço & $\begin{array}{c}\text { Estimativa de Valor } \\
\text { mensal (RS) }\end{array}$ \\
\hline Travessia (R) & $27.000,00$ \\
\hline Ingresso (R) & $22.750,00$ \\
\hline Aluguel bicicleta (R) & $45.000,00$ \\
\hline Aluguel charrete (R) & $54.000,00$ \\
\hline Lanchonete (R) & $13.600,00$ \\
\hline Total (R) & $162.400,00$ \\
\hline Manutenção (30\%) (D) & $48.600,00$ \\
\hline $\begin{array}{c}\text { Pessoal e Despesas } \\
\text { administrativas (D) }\end{array}$ & $91.000,00$ \\
\hline Total final & $22.750(+)$ \\
\hline
\end{tabular}

É importante destacar que o turista iria pagar pela experiência uma média de $\mathrm{R} \$ 40,00$ (ingresso e alimentação) a R\$90,00 (ingresso, alimentação e passeio de bicicleta, por exemplo). Cabendo lembrar que nisto ele irá gastar com alimentação como o faria em qualquer lugar e ainda optaria por incluir algo a mais na sua experiência, como um passeio de charrete ou bicicleta.

Investimento inicial:

Como a proposta trabalha apenas o ordenamento do potencial atualmente existente, onde já se tem a estrutura inicial disponibilizada, a exemplo dos equipamentos (bicicletas, charretes, itens de cozinha) bem como estruturas (edificações para abrigar o restaurante/lanchonete, espaço já em utilização pelo estacionamento, portaria em funcionamento, centro de visitantes já instalado, dentre outros; entende-se que o investimento inicial é de pequeno vulto, estando voltado principalmente para pequenas reformas e investimentos de baixo valor. Com relação à depreciação dos ativos imobilizados, estima-se a vida útil dos mesmos em 10 anos e taxa de depreciação a 10\% anual (BRASIL, 2019).

Entende-se ser necessário algumas pequenas obras, a exemplo de ampliação do número de banheiros e de adaptação do sistema de fossas, que é utilizado atualmente na unidade. Tendo por 
balizamento o preço do $\mathrm{m}^{2}$ para reformas de padrão comercial normal (CSL 8) a um custo de R\$1.400,00 (SINDUSCON, 2019) e considerando a construção/reforma efetiva de $100 \mathrm{~m}^{2}$ de áreas diversas, tem-se a estimativa de despesas com investimentos desta natureza da ordem de $\mathrm{R} \$ 140.000,00$

Presume-se ainda gastos da ordem de $\mathbf{R} \$ 60.000,00$ com a aquisição de materiais diversos, a exemplo de itens de cozinha, cama e banho, a serem utilizados tanto no restaurante/lanchonete como nos abrigos de montanha bem como adequações junto à área de estacionamento. Portanto, o investimento inicial está estimado em R\$200.000,00.

Dentre diversas estratégias possíveis, a exemplo daquelas relacionadas a linhas de crédito junto a instituições financeiras privadas, tem-se a alternativa de se utilizar recursos oriundos do Banco Nacional do Desenvolvimento - BNDES, cujas taxas de juros são da ordem de 13\% ao ano, existindo normalmente uma carência de até três meses onde paga-se apenas os juros do financiamento contratado.

Ademais, o programa de financiamento do BNDES considera que investimentos realizados pelo solicitante podem ser considerados como contrapartidas e em casos de estarem associados a concessões/autorizações de serviços públicos podem até mesmo serem reembolsados (BNDES, 2019). Destaca-se que os diversos equipamentos já adquiridos pelos associados, como bicicletas, animais de montaria e acessórios, no conjunto, podem ser utilizados como garantia de pagamento.

A simulação realizada no site da instituição em outubro de 2019 demonstra que para o valor estimado de R\$200 mil, ter-se-iam três meses de carência, com taxa de remuneração do agente financeiro a 6,2\% e com a projeção da inflação anual a 3,63\%, tem-se o primeiro pagamento iniciando no quarto mês apenas dos juros e taxas (R\$6,5 mil) e posteriormente, parcelas decrescentes mensais de R\$11.6 mil a R\$9.6 mil até o último mês, totalizando R\$230.367,21.

Logo, seria uma estratégia muito importante a adoção destes empréstimos pela associação hipotética, haja visto que, com este financiamento, ter-se-ia a estruturação de todo o sistema em uma rodada inicial, que passará a gerar fluxo de caixa positivo de cerca de R\$23 mil mensais inicialmente. Assim, se a associação reservar cerca de R\$10 mil mensais para a posterior quitação do empréstimo até o prazo estipulado (24 meses), restaria ainda cerca de R\$13 mil para serem utilizados efetivamente junto aos objetivos sociais da referida associação.

Considera-se também a participação do próprio ICMBio neste processo de estruturação e manutenção, dado que trata-se de investimentos em sua área. É relevante citar que a instituição possui contrato específico de manutenção predial que poderia abarcar parte das ações previstas. Como fonte de recursos para sustentar tais atividades contratuais, cita-se a possibilidade de se utilizar recursos oriundos da Compensação Ambiental, a qual a UC possui valor atrelado, conforme dados do Painel Dinâmico do ICMBio (ICMBio, 2019).

Projeções:

Esta modelagem abrange apenas uma das entradas do Parque Nacional da Serra do Cipó, que possui área de 33 mil hectares, logo, é plenamente viável perceber que outras Portarias poderiam ser abertas neste tipo de arranjo proposto, beneficiando comunidades de outros municípios. Atualmente, apesar de não haver portarias nestes outros locais, ocorre visitação não ordenada, sem o menor controle por parte do ICMBio e sem nenhum ganho para a população local.

Considerando a instalação de pelo menos 6 portarias na Unidade (município de Jaboticatubas, Santana do Riacho, Nova União (distrito Altamira), Itabira (distrito Serra dos Alves), Itambé do Mato Dentro (Distrito Cabeça de Boi) e Morro do Pilar (Alto Palácio), e tendo a estimativa de 30 pessoas 
trabalhando com ecoturismo inicialmente em cada local e gerando um fluxo de caixa positivo de ao menos 10 mil, tem-se que o Parque Nacional da Serra do Cipó tem o potencial de gerar cerca de 180 "empregos" e angariar junto com a sociedade local cerca de R\$60 mil mensais para uso em prol da sociogeobiodiversidade em boa parte do território das duas UCs.

Destaca-se o fato de que tal fluxo positivo de caixa pagando impostos onde não se pagava, gerando renda onde era inexistente, trazendo para mercado de trabalho cerca de 180 pessoas e ainda incentivando circulação de dinheiro na economia local promovendo dinamização, a exemplo de novos comércios locais voltados para suprir as atividades ecoturistas como loja de peças para bicicletas charretes, materiais esportivos, itens de alimentação, dentre outros.

Também se registra o potencial para ampliar o negócio tanto em outras atividades do ramo de ecoturismo (pousada, caiaque, observação noturna, artesanato, etc.) como em outras localidades, a exemplo dos outros municípios onde a UC APA Morro da Pedreira possui atrativos com potencial de receber turistas.

\section{Discussão}

Conforme Cruz (2003), é indubitável a capacidade do turismo em alterar territórios para que a atividade aconteça, o que deve ser objeto de especial atenção a todos que buscam fomentar a atividade, em especial no contexto das Unidades de Conservação, dado que o ônus da atividade, como degradação ambiental, prejuízos sociais e repartição injusta dos benefícios da sociobiodiversidade são a grosso modo concentrados no local receptor do turismo. De acordo com Botelho \& Rodrigues (2016), tal concentração de impactos resulta em perspectivas excludentes, transferindo os benefícios das áreas protegidas das classes média e baixa para as elites.

Rodrigues \& Godoy (2013) demonstram que as opções entre as modalidades de delegação de prestação de serviços públicos são influenciadas pelas diferentes formas de conceber o Estado e a sua atuação nas esferas pública e privada. Seriam então opções a disposição do ente governamental para auxiliá-lo na implantação de determinado projeto de desenvolvimento, sendo estas opções a autorização, permissão, concessão, parceria com Organização Social e mesmo Gestão Compartilhada.

Por sua vez, o ICMBio tem apostado fortemente no modelo das concessões de serviços turísticos nas UCs para empresas do ramo, havendo inclusive em sua estrutura administrativa um setor para tratar especificamente deste assunto. Sobre as outras possibilidades, a exemplo de autorizações e permissões e mesmo Turismo de Base Comunitária, apesar de haverem exemplos isolados na instituição destas modalidades (RODRIGUES, \& ABRUCIO 2019; ICMBio, 2020), há de se considerar que tais iniciativas ainda não são tratadas ao mesmo nível de prioridade e investimentos que as concessões enquanto estratégia institucional.

Apesar de ter certas externalidades positivas, o modelo de concessões colocado em prática nas UCs Federais demonstra ser necessário um maior alinhamento deste com a Missão Institucional da autarquia e seu planejamento estratégico, dado características como alto custo das UCs com contratos de concessão, do controle gerencial que necessita de aperfeiçoamentos, da repartição desequilibrada dos benefícios da atividade principalmente junto as comunidades locais bem como de situações envolvendo impactos ambientais e sociais da atividade. Acrescenta-se ao panorama acima o fato de que normalmente nos processos de concessão de serviços de turismo em Unidades de Conservação, o lucro da empresa acaba sendo direcionado não para aplicação no local de origem, mas em outros investimentos fora do contexto onde a UC está inserida, diminuindo assim as chances de se alavancar ainda mais a economia local. 
Uma outra situação que deve ser levada em conta no tocante às concessões de serviços turísticos nas Unidades de Conservação Federais é o fato de a quem cabe os investimentos naquilo que gera o negócio, ou seja, o ônus de manter o ecossistema equilibrado, que resulta em belezas cênicas singulares e atrativos específicos, a exemplo de quedas d'água, sendo que tal ônus ainda recai exclusivamente ao ICMBio, o que aumenta o desafio da gestão. Apenas a título de comparação, no sistema de concessão de abastecimento de água em vigor em vários municípios brasileiros, cabe à empresa autorizada a manutenção de áreas especialmente protegidas que geram o recurso hídrico. Em Minas Gerais, por exemplo, a COPASA tem participação ativa na administração de diversas áreas de mananciais, mesmo estas estando inseridas em Unidades de Conservação Estaduais (EUCLYDES, 2011).

No contexto do Parque Nacional da Serra do Cipó, de que as ações de manejo ambiental recaem apenas sobre o ICMBio, tem-se 10 mil hectares para cada servidor, é pouco provável que uma eficácia de manejo seja alcançada, situação ainda agravada pelo fato de que boa parte do trabalho da equipe dá-se no escritório e pelo fato da demanda por recursos adequados para este monitoramento (veículos, GPS, câmera fotográfica, equipe) não ser adequada a realidade administrativa da UC. Conforme Bruner et al (2001), a presença institucional é tida como a garantia eficaz para o cumprimento dos objetivos da criação da UC, ao atuar ao mesmo tempo inibindo ações ilícitas bem como promovendo ações em prol da conservação da biodiversidade. Assim sendo, no contexto de opções para o turismo, a busca por parceiros e estratégias que satisfaçam a necessidade da presença institucional deveria ser uma meta a ser perseguida e tratada como prioridade, até porque, para a atividade ecoturística, a paisagem natural necessita estar preservada.

De acordo com esta estratégia, é plenamente possível que em um arranjo de Turismo de Base Comunitária envolvendo parcerias, autorizações e permissões, a Instituição possa lançar mão de contrapartidas em serviços por parte da comunidade. Tais serviços devem estar atrelados a própria atividade econômica no contexto da UC, como seria o caso de monitoramento de biodiversidade ou incêndios florestais e outras pressões antrópicas, fluxo de turistas ao longo do circuito autorizado para a atividade em tela, seja ciclismo, trekking ou outra modalidade. Com esta estratégia, a UC ganha com a presença institucional perene através de parceiros que necessitam que tais locais se mantenham preservados para o bem de seu negócio, ao contrário de funcionários que apenas recebem um salário para permanecer em tais locais muitas vezes sem um interesse em comum com o da instituição gestora da área protegida, que seria o caso de guaritas com vigilantes de empresas terceirizadas. Ademais, a autorização/permissão pode prever que os procedimentos de estabelecimento de estruturas bem como serviços de limpeza, vigilância e manutenção sejam abarcados pelo parceiro e desta forma a Instituição teria a possibilidade de economizar recursos dada a diminuição de gastos pretendida.

Por tudo o que foi apresentado, defende-se que o modelo de concessão de serviços turísticos fomentado pelo ICMBio não seria a melhor opção para o Parque Nacional da Serra do Cipó, dado que a UC apresenta um potencial para o desenvolvimento do Turismo de Base Comunitária que aparentemente seria mais eficaz e eficiente e com maior alinhamento à Missão Institucional do ICMBio. Corroborando esta opção, uma outra vertente que deve ser analisada se refere ao fato de que as concessões ditas exitosas (Tijuca e Foz do Iguaçú) normalmente estão associadas a um número de visitantes na casa dos milhares por ano. No caso da Serra do Cipó, o número de visitantes, apesar de estar em rápida ascensão, é tido informalmente como ainda não sendo atrativo para atividades de concessão de serviços turísticos. Entretanto, o mesmo já se encontra em níveis que ultrapassam limites estabelecidos no Plano de Manejo (ICMBio, 2009), uma vez que a média diária seria de 216 visitantes, sendo que em finais de semana prolongados já se registrou a entrada de mais de 1000 
pessoas nas duas portarias da UC. Em qualquer das duas situações (média ou real), este número supera em muito o limite de pessoas estabelecido para os atrativos, que são na faixa de 50/dia.

Tem-se com isto que, para tornar a UC mais atrativa para a concessão, deve-se investir em ter mais visitantes, porém isto trará conflito com o próprio manejo ambiental recomendado para a área. Por outro lado, iniciativas de TBC estão mais associadas a uma experiência mais profunda entre o turista e o morador local, situação em que se trabalha não a quantidade, mas a qualidade. Esta dualidade se relaciona a qual projeto de sociedade se deseja contribuir com as Políticas Públicas planejadas e executadas. A discussão sobre a importância do TBC enquanto estratégia de gestão já está consolidada no ICMBio (ICMBio, 2020), porém a mesma esbarra em recursos e estratégias para sua operacionalização.

\section{Alternativa ao modelo proposto}

Uma outra possibilidade é a busca de sinergia dos pontos positivos de cada um dos modelos (Concessão/TBC) e a possibilidade de atuação em rede e em formatos múltiplos. Por exemplo, podese criar múltiplos arranjos gerencias com características de ambos modelos (TBC e Concessão), de acordo com as realidades de cada contexto. Neste sentido, poder-se-ia lançar mão da mesma estratégia já em uso para outras áreas como saneamento, energia elétrica e transporte público e utilizar o chamado "subsídio cruzado", que consiste em um grupo de consumidores pagar preços mais elevados para subsidiar outros grupos em situação de vulnerabilidade social. Tal estratégia, na área de saneamento se traduziu em conceder os serviços para as empresas atuarem em lotes de municípios e não em municípios isolados, de forma que o lucro obtido nos municípios com características de maior interesse para as empresas (PIB elevado e população numerosa) sustentava o prejuízo das operações em municípios em situações menos favoráveis (PIB mediano e baixo adensamento populacional).

Esta lógica, se aplicada ao contexto das concessões de serviços turísticos em Unidades de Conservação tem o potencial de beneficiar diversas UCs e comunidades locais cujo potencial para o turismo se encontra latente, que não despertam interesse das empresas do ramo, mas que podem ser objeto de ações específicas, como fomento do TBC. Desta forma, seriam editais de concessão em lotes e não para uma UC apenas, devendo a composição destes lotes apresentar características factíveis para ambas as partes (Poder Concedente e empresa Concessionária). Neste formato, as empresas poderiam repensar sua estratégia de negócio e em vez de serem a operadora de todo o circuito, gastando sua energia até mesmo nas tarefas mais basais, passariam a atuar mais no cerne do negócio, que poderia ser visto como "possibilitar vivências socioambientais", ou algo do gênero. Para a empresa, seria utilizar as estratégias de "branding", de gestão da marca, voltada a posicionar a imagem do produto influenciando a escolha do público-alvo, e como descrito em Pereira et al (2018), "através do reforço de boa reputação, estímulo a lealdade, garantia de qualidade, veiculação de uma percepção de maior valor permitindo que um produto seja vendido a um preço superior, e garantia ao comprador de uma sensação de afirmação e de uma comunidade imaginária de valores partilhados"

Para as comunidades locais, seria a oportunidade de operar via terceirização as atividades básicas, como seria o caso das lanchonetes, passeios e atividades similares, possibilitando atuar como empreendedor. Nesta modelagem, ganharia a empresa por passar a se concentrar no foco do negócio, contrabalanceando a perda das receitas diretas com redução drástica de custos e ganhariam as comunidades que teriam nessa estratégia a possiblidade de iniciar no mundo corporativo e ganhar vivência para um dia também gerir o próprio negócio. 
Acerca desta vivência corporativa a ser construída pelas comunidades locais, a receita mensal simulada neste estudo de R\$162 mil (logo cerca de R\$2 milhões anuais) coloca a hipotética associação já no nível de Empresa de Pequeno Porte, cuja classificação, baseada no faturamento, inclui as empresas cujas receitas estejam entre $\mathrm{R} \$ 360$ mil e $\mathrm{R} \$ 4,8$ milhões anuais, de acordo com a Lei Complementar 123/2006. Logo, se atendo apenas ao aspecto financeiro, já é um passo largo para se avançar rumo a concorrer futuramente nos processos de concessões por conta própria.

\section{Considerações finais}

Os resultados deste estudo demonstram que é totalmente factível que o ecoturismo nas Unidades de Conservação possa se dar também por um viés de base comunitária, tendo este o potencial de reverter diversas situações-problemas enfrentados a nível local, tanto pelas comunidades quanto pela gestão da UC, possibilitando eficiência e eficácia na proteção do patrimônio natural e promoção do desenvolvimento sustentável. Entende-se que o ICMBio poderia investir neste tipo de arranjo gerencial dado o grande potencial que o mesmo possui de trazer sinergia a inciativas de TBC em andamento nas UCs ou possíveis de se iniciar, facilitando o caminho a ser trilhado para o cumprimento de sua Missão Institucional bem como promovendo Valores Constitucionais. O argumento é reforçado pelo fato de que a maioria das UCs onde seria possível desenvolver o turismo não se encontra em um nível atrativo para as concessões.

Por fim, a proposta da adoção de modelos mistos envolvendo aspectos típicos de concessão e de Turismo de Base Comunitária dialoga bem com o Conceito de Criação de Valor Compartilhado, onde o desenvolvimento de determinada atividade econômica está estreitamente vinculado à saúde da comunidade do entorno desta atividade, onde busca-se a melhoria de características diversas para ambas as partes (PORTER \& KRAMER, 2011), sendo possível aplica-lo no contexto das atividades de turismo nas UCs, propiciando benefícios a vários pontos da rede turística. 


\section{Referências}

ALMADA, E. D.; ANAYA, F. C.; MONTEIRO, F. T. (2016). The people of the Mountains: the Biocultural Heritage of the Espinhaço Range in Minas Gerais State, Brazil. In: FERNANDES, G.W. (Ed). Ecology and Conservation of Mountaintop Grasslands in Brazil. Suíça, Springer International Publishing, p. 479-499. AMARAL, K. C. A. V. A gente cuida do cerrado porque ele cuida de nós. Dissertação Mestrado. Universidade do Estado de Minas Gerais. (2018). 136 fls. Disponível em: <http://www.ppgeduc.uemg.br/wp-content/uploads/2018/08/DISSERTA\%C3\%87\%C3\%830-KELEAMARAL.pdf>. Acessado em 01/10/2020.

ANAIYA, F. C.; SOUZA, M. C. F. (2014). Conflitos ambientais territoriais no Parque Nacional da Serra do Cipó. Revista Desenvolvimento Social - Edição Especial.

BANCO NACIONAL DE DESENVOLVIMENTO ECONÔMICO E SOCIAL - BNDES. (2019). Manual do financiamento. Brasília. DF.

BETTI, P.; DENARDIN, V. F. (2013). Turismo de Base Comunitária em Unidades de Conservação: justiça ambiental para o desenvolvimento local. Revista Brasileira de Ecoturismo. São Paulo, v. 6, n. 4. pp. 176-190.

BOTELHO, E. S.; RODRIGUES, C. G. O. (2016.). Inserção das atividades de base comunitária no desenvolvimento do turismo em parques nacionais. Caderno Virtual de Turismo, Rio de Janeiro, v. 16, n.2, p.280-295, ago.

BRASIL. (2019). MINISTÉRIO DA FAZENDA. SECRETARIA DO TESOURO NACIONAL. Manual SIAFI Sistema Integrado de Administração Financeira do Governo Federal. Brasília. DF. Disponível em: $<$ https://conteudo.tesouro.gov.br/manuais/index.php?option=com_content\&view=article\&id=1565:0 20330-depreciacao-amortizacao-e-exaustao-na-adm-dir-uniao-aut-e-fund\&catid=749\&ltemid=700>. Acesso em 15/10/2019.

BRUNER, A. G.; GULLISON, R.E.; RICE, R.E.; FONSECA, G.A.B. (2001). Effectiveness of parks in protecting tropical biodiversity. Science. v.291, p. 125-127.

CARDOSO, C. V. As interfaces socioambientais de um lugar em reconstrução: Distrito Serra do Cipó/Minas Gerais. 2008. Dissertação de mestrado. UFMG. Disponível em: <https://repositorio.ufmg.br/handle/1843/MPBB-8JQFFZ>. Acesso em 13/09/2019.

CRUZ, R. de C. (2003). A. Introdução à geografia do turismo. 2 ed. São Paulo, Roca.

EUCLYDES, A. C. P. (2011). O que há de especial na proteção dos mananciais? Um estudo sobre as Áreas de Proteção Especial - APEs - do Eixo Sul da Região Metropolitana de Belo Horizonte. Geografias. V. 7, n. 1.

GONTIJO, B. A ilusão do ecoturismo na Serra do Cipó MG, o caso de Lapinha. Abril de 2003. 210 f. Tese (Doutorado em Desenvolvimento Sustentável) - Universidade de Brasília. Brasília, DF, 29 de abril de 2003.

INSTITUTO CHICO MENDES DE CONSERVAÇÃO DA BIODIVERSIDADE - ICMBIO. (2009). Plano de Manejo do Parque Nacional da Serra do Cipó. Disponível em: < http://www.icmbio.gov.br/portal/unidadesdeconservacaos. Acesso em 12/09/2019.

INSTITUTO CHICO MENDES DE CONSERVAÇÃO DA BIODIVERSIDADE - ICMBIO. (2013). Processo administrativo 02145.000003/2013-57. Brasília. DF.

INSTITUTO CHICO MENDES DE CONSERVAÇÃO DA BIODIVERSIDADE - ICMBIO. (2019). Incêndios em unidades de conservação federal. Disponível em: < https://www.gov.br/icmbio/pt-br/acesso-ainformacao/dados-abertos/arquivos/incendios-em-unidades-de-conservacao-

federais/incendios_em_unidades_de_conservacao_federal.xlsx>. Acesso em 10/0310/2021. 
INSTITUTO CHICO MENDES DE CONSERVAÇÃO DA BIODIVERSIDADE - ICMBio. (2019). Informações sobre Compensação Ambiental. Painel Dinâmico. Disponível em: <http://qv.icmbio.gov.br/QvAJAXZfc/opendoc2.htm?document=painel_corporativo_6476.qvw\&host $=$ Local\&anonymous=true>. Acesso em 13/09/2019.

INSTITUTO CHICO MENDES DE CONSERVAÇÃO DA BIODIVERSIDADE - ICMBIO. (2020). Relatório anual de gestão. Disponível em: < https://www.icmbio.gov.br/portal/images/stories/Acesso_Informacao/Auditorias/Processos_de_Co ntas_Anuais/relatorio_de_gestao_Ano_2019.pdf>. Acesso em 01/10/2020.

MIELKE, E. J. C.; PEGAS, F.V. (2013). Turismo de Base Comunitária no Brasil. Insustentabilidade é uma questão de Gestão. Turismo em Análise, v. 24, n. 1.

MINISTÉRIO DA ECONOMIA. (2019). Estudo sobre a composição dos custos dos valores limites Serviços de Limpeza e Conservação. Unidade da Federação Minas Gerais. DF.

MINISTÉRIO DA TRANSPARÊNCIA E CONTROLADORIA GERAL DA UNIÃO - MTCGU. Relatório $n^{\circ}$. 201601851/2016. Disponível em: <https://auditoria.cgu.gov.br/download/10369.pdf>. Acesso em 01/10/2020.

MINISTÉRIO DO MEIO AMBIENTE - MMA. (2018). Portaria 831/2018. Brasília. DF. PEREIRA, L. A.; LIMBERGER, P. F. FLORE, L. C. S. (2018). Identificação dos aspectos conceituais e elementos que constituem o Branding e Destination Branding. Revista Turismo em Análise, v. 29, n. 1. PITA, F. A. (2013). A economia solidária e o Estado: lições a partir de um caso concreto. Revista Direito Mackenzie, v. 7, n. 1.

PONTES JUNIOR, E. (2016). Análise da efetividade de gestão do Parque Nacional do Descobrimento/BA. Dissertação de mestrado. Montes Claros, Disponível em: <http://www.ppgcb.unimontes.br/images/bibtex/Junior_2016_Analisedaefetividade.pdf>. Acesso em 02/08/2018.

PORTER, M.E.; KRAMER, M. R. (2011), The big idea: Creating shared value. Harv. Bus. Rev. 89, 62-77. RODRIGUES, C. G. O.; ABRUCIO, F. L. (2019). Parcerias e concessões para o desenvolvimento do turismo nos parques brasileiros: possibilidades e limitações de um novo modelo de governança. Revista Brasileira de Pesquisa em Turismo. São Paulo, n. 13, p.105-120.

RODRIGUES, C.G.O.; GODOY, L.R.C. (2013). Atuação pública e privada na gestão de Unidades de Conservação: aspectos socioeconômicos da prestação de serviços de apoio à visitação em parques nacionais. Desenvolvimento e Meio Ambiente, v. 28, p. 75-88.

SINDICATO DA INDÚSTRIA DA CONSTRUÇÃO CIVIL NO ESTADO DE MINAS GERAIS - SINDUSCONMG. (2019). Tabela dos Custos Unitários Básicos de Construção. Referência: setembro de 2019. Disponível em: <http://www.sinduscon-mg.org.br/wpcontent/uploads/2019/10/tabela_cub_setembro_2019.pdf>. Acesso em 15/10/2019.

SOARES, M. (2007) Impactos do turismo: os efeitos do ecoturismo em Unidades de Conservação. Revista Coordenadas - Turismo e Gerenciamento. Itajaí, v. 2, n. 2.

Word Wide Fund for Nature - WWF. (2018). Financiamento público em meio ambiente. Um balanço da década e perspectivas. Brasília. DF. Disponível em:< https://www.wwf.org.br/?63822/uniao-estadosmunicipios-orcamento-meio-ambiente>. Acesso em 10/06/2018. 